\title{
Translating e-pain research into patient care
}

\section{Authors:}

Brian E. McGuire ${ }^{a}{ }^{*}$, Ellen M. Henderson ${ }^{b}$, Patrick J. McGrath ${ }^{c}$

a School of Psychology and Centre for Pain Research, National University of Ireland, Galway, Ireland, b Louis Dundas Centre for Children's Palliative Care, UCL Great Ormond Street, Institute of Child Health, London, United Kingdom,

c ResearchServices, IWK Health Centre, Halifax, NS, Canada

\section{Conflict of interest statement}

The authors have no conflicts of interest to declare.

\section{Funding}

B. McGuire's post is supported by a Health Research Board Ireland, Research Leader's Award. E. Henderson's post is supported by Great Ormond Street Children's Charity (G25 508605 2LGB). P. McGrath's post is supported by a Canada Research Chair award.

*Corresponding author. Address: School of Psychology, National University of Ireland, University Road, Galway, Ireland H91 EV56. E-mail address: Brian.mcguire@nuigalway.ie (B. McGuire). Tel: 1353 (0)91493266; fax 1353 (0)91534930. 


\section{Introduction}

Recently, a call was made to expand the availability of pain self-management for the public, 29 but several obstacles limit access to pain services such as distance, cost, and availability.32,39 Technology-based interventions can help with access to pain management, and consideration of these opportunities is timely given service pressures, changing consumer preferences, and the burgeoning ownership of personal computers and smartphones. In that context, we have described (1) the features of e-pain technologies, (2) the challenges in developing e-pain technologies, (3) the existing evidence in relation to technology based pain management, (4) the debate regarding regulation of e-pain treatments, and (5) the likely steps for future development of these interventions.

\section{What are e-pain technologies?}

Technology-based pain management can be Internet based or mobile device based, or a mixture of both technologies-we use the term e-pain technologies when referring to both. E-pain technologies can be divided into 3 main types: (1) interventions for managing pain (which tend to be primarily psychological and activity-focused treatments); (2) pain symptom diaries (mostly on mobile phone apps); and (3) wearable devices for collecting real time data such as exercise data, sleep activity, and other physiological data. Figure 1 depicts a conceptual e-pain treatment programme with both a web-based platform and a mobile-based component, where the programme both delivers and receives information from the patient and can tailor the intervention based on the patient's responses.

In this review, we have focused on psychological treatment studies rather than symptom monitoring and we have divided the review into Internet-based interventions and mobile device interventions. We propose that there is an emerging evidence base for web-based interventions and that the next steps involve more nuanced effectiveness research, followed by credentialing and implementation. Mobile technologies are at an earlier stage of development-while they hold out the potential for wide-scale uptake in the future, 38 at present there is insufficient evidence to recommend wide uptake. More research is needed on acceptability, feasibility, and effectiveness.

\section{Challenges in the development and evaluation of e-pain interventions}

A recent review identified several limitations in the design of pain management apps, 24 similar considerations apply to web-based technologies but we contend that web-based interventions have successfully addressed some of these limitations. These limitations are considered further here:

(1) Limited capability to allow for personalization of treatment-almost all clinical interactions involve the clinical judgment of the clinician and the negotiation and agreement of a course of treatment, with modifications made based on patient feedback. This complex review and revise circuit poses a technology challenge, where treatment algorithms must be developed to take account of a wide range of possible combinations of variables. The technology to do this exists-several recent programmes have incorporated variants of this feature.1,17,21

(2) Lack of involvement of health professionals in development and evaluation of apps, especially those available in app stores. For example, 2 studies of pain apps for smartphones found that only $14 \%$ to $18 \%$ of the apps were created with scientific or clinical expertise and none of the apps 
reported the psychometric properties of the diaries.19,32 In contrast, most of the Internet interventions have been developed by clinicians and researchers in academic institutions. Although the involvement of health experts is not a guarantee of effectiveness, we believe it reduces the risk of unsafe and ineffective treatments.

E-pain interventions deliberately seek to minimise the "real-time" involvement of clinicians,18,20,22 but we do not know if (or how much) therapist contact is needed or in what format, to engage patients and maximise clinical outcomes. A recent Internet intervention for chronic pain was equally effective with either optional or no therapist support as when there was scheduled therapist contact.10 Although a therapeutic relationship can develop when therapy is delivered over the phone, 26 we do not know if this relationship can be replicated without contact between the practitioner and service user or indeed whether this relationship is necessary.

(3) Lack of a foundation in current research or behavioural theories. If an intervention purports to offer therapeutic potential, then it is reasonable to seek to identify the effective elements of the treatment. Knowledge about the behaviour change techniques used and any guiding theoretical models can help with replication of interventions and development of new treatment content. With the exception of web-based Cognitive Behavioral Therapy (CBT) (eg, Refs. 9-11,21,25,31,35) and Acceptance and Commitment Therapy (ACT) interventions (eg, Refs. 5,37), few studies describe a theoretical basis for the intervention or identify the possible mechanisms of action.

(4) Lack of scientific evaluation through feasibility or effectiveness testing. For the consumer and a technology developer, a "successful" technology is one that is used by many people, whereas scientists and clinicians want to know whether the technology is effective. Before e-pain interventions are widely used by clinicians, there is a need to answer some fundamental questions:

- Are the interventions fit for purpose-safe and clinically effective?

- What are the effective components?

- What is the best format for delivery of the intervention (is therapist contact needed, how much, how often)?

- Who benefits from the interventions?

- Are they cost-effective?

In the next section, we review the evidence for the effectiveness of e-pain interventions.

\section{Are e-pain interventions effective?}

The evidence for e-pain technologies differs depending on the primary delivery format (web based or mobile based). Two Cochrane reviews found evidence that Internet-based treatments reduced pain, disability, depression, and anxiety in adults and children after the intervention,12,15 giving cause for optimism.

Since then, at least 9 more studies have been published, focused equally on adults and children. In Table 1 (suppl, available online at http://links.Iww.com/PAIN/A327), we have provided a selected and annotated summary of some of the recent papers in the area, looking separately at mobile devices and web-based programmes. As is evident from the summary, there is considerably better evidence to support web-based interventions but an absence of evidence to yet recommend mobile app interventions. 
In relation to mobile apps, there remains a need for studies that examine the feasibility, acceptability, and effectiveness of these interventions. If the effective web-based interventions can be adapted for mobile devices, then there is good reason for optimism, because smartphone usage is now widespread and this means many more people could get access to pain management interventions.

For web-based interventions, Table 1 (suppl) shows a clear trend of effectiveness, with stronger evidence emerging in more recent studies-possibly due to better quality studies, better technology and treatment interface, better awareness of effective components or a combination of these factors. The studies also show evidence of good acceptability as indicated by excellent adherence, especially in more recent studies where personalizing the nature of the communication appears to have been helpful, eg, having a name and photo or video of the (virtual) therapist, and where regular communication was important, even if that was automated. Qualitative studies also indicate that health consumers are open to using e-pain methodologies.33

As well as examining clinical effectiveness, we need more data on the cost-effectiveness of e-pain interventions-while e-pain services may intuitively appear likely to be cheaper than face-to face services because they reduce the need for face-to-face contact,10 we do not know how this compares to the costs associated with development and support of e-pain interventions.

This area requires focused attention from the research community.

\section{Should e-pain interventions be regulated?}

The proliferation of e-pain technologies raises the question of whether there should be some form of credentialing and/or regulation of e-therapies. In the traditional health sector, there is some safety and recourse for patients who attend clinicians with recognized qualifications, recognized affiliations, and who practice under a professional code of ethics. Unfortunately, these protections are less easily secured when patients avail of e-pain interventions that are simply accessed via an app or web page that may be based in other jurisdictions. In the United States, the Federal Drug Administration has proposed a set of regulations to tackle the issue of determining which health apps will be regulated.14 Some clinicians have critiqued this proposed regulatory approach for its cumbersome registration process for app developers and the lack of pace of regulation in comparison with technology development. 2

The alternative to formal oversight of e-pain technologies is to use self-regulation and codes of good practice. There are ethical guidelines for Internet-mediated research4 and for Internet-mediated clinical interventions,6,7 and we contend that delivery of e-pain services should be subject to the same ethical guidelines as apply to face-to-face treatments. If a health professional, on the basis of good evidence, recommends an app then the ethical mandate is not any greater than a health professional prescribing another treatment. The problem is the health professional often has no way of knowing which e-pain technology is effective or appropriate for the patient. Thus, there is an imperative to ensure that e-pain technologies are appropriately evaluated and disseminated with a "stamp of approval" on which prescribers and consumers can rely.

\section{Improving access to e-pain technologies}


In line with a recommended model of stepped care for psychological support in pain management,34 e-pain interventions can operate as standalone low-intensity interventions that can be offered as a firstline of treatment. Even at this level, interventions can be individually tailored using software such as IRIS.41 At a second level, clinicians can use e-pain programs to supplement their face-to-face treatment of more complex presentations.

There are many e-clinics and e-programs already in operation in research institutions, and the private sector and several others have successfully scaled up to reach a wide audience (eg, Refs. $3,13,27,28,30,36,40)$. But many effective programs remain within the confines of academic institutions and there are several major challenges involved in making effective e-interventions widely available within existing service structures that assume face-to-face contact. Several groups have made recommendations regarding uptake of e-pain technologies (American College of Physicians, 8 Canadian Medical Association, 6 IMS Institute for Healthcare Informatics 20) and have suggested a number of criteria for the use of e-pain technologies, summarized here alongside our own views in what we consider to be the necessary steps for wider uptake:

(1) A curated list of interventions that are (a) usable and (b) have evidence for effectiveness

(2) Endorsement by an appropriate organization (eg, a professional body)

(3) Practice infrastructure for e-technology prescribing and monitoring progress

(4) Training for health care providers to prescribe and supervise e-pain interventions

(5) Mechanism to monetise prescribing and monitoring

(6) Meets privacy and security regulations

(7) Protection of the prescriber and the institution from liability arising from technology usage

(8) Low or no cost for the user

(9) Has an impact on patient outcomes

(10) Compatible with existing health record systems

(11) A system to monetise the intervention owner so that the service can be maintained, improved, and expanded.

When examining ways of introducing new treatments into existing health systems, consideration can also be given to use of other communication systems such as social media and games based media to reach a wider audience. For example, there is a move toward the use of "gamification" 23 or "serious games" to offer treatments embedded within online games to people for whom this approach might improve access and engagement, such as children and young adults.

\section{Conclusions}

The prospects for e-technologies for chronic pain are positive but there are several challenges. For example, evidence of efficacy in highly controlled studies does not always translate into evidence of effectiveness at the level of health service implementation.16 We contend that there is sufficient evidence to support the wider implementation of large-scale pragmatic clinical trials delivered via web-based programs, but there is a lack of evidence to support wider implementation of trials 
delivered through mobile devices. Efficacy studies of mobile-based interventions are likely to emerge over the next 2 years.

Patients want interventions that are easy to access, secure, effective, and have minimal or no cost. Health care providers want interventions that they will get paid for prescribing, will help many patients, will not expose them to liability, and are easy to prescribe eg, from within the electronic health record. E-pain technologies offer the potential to satisfy these requirements. 


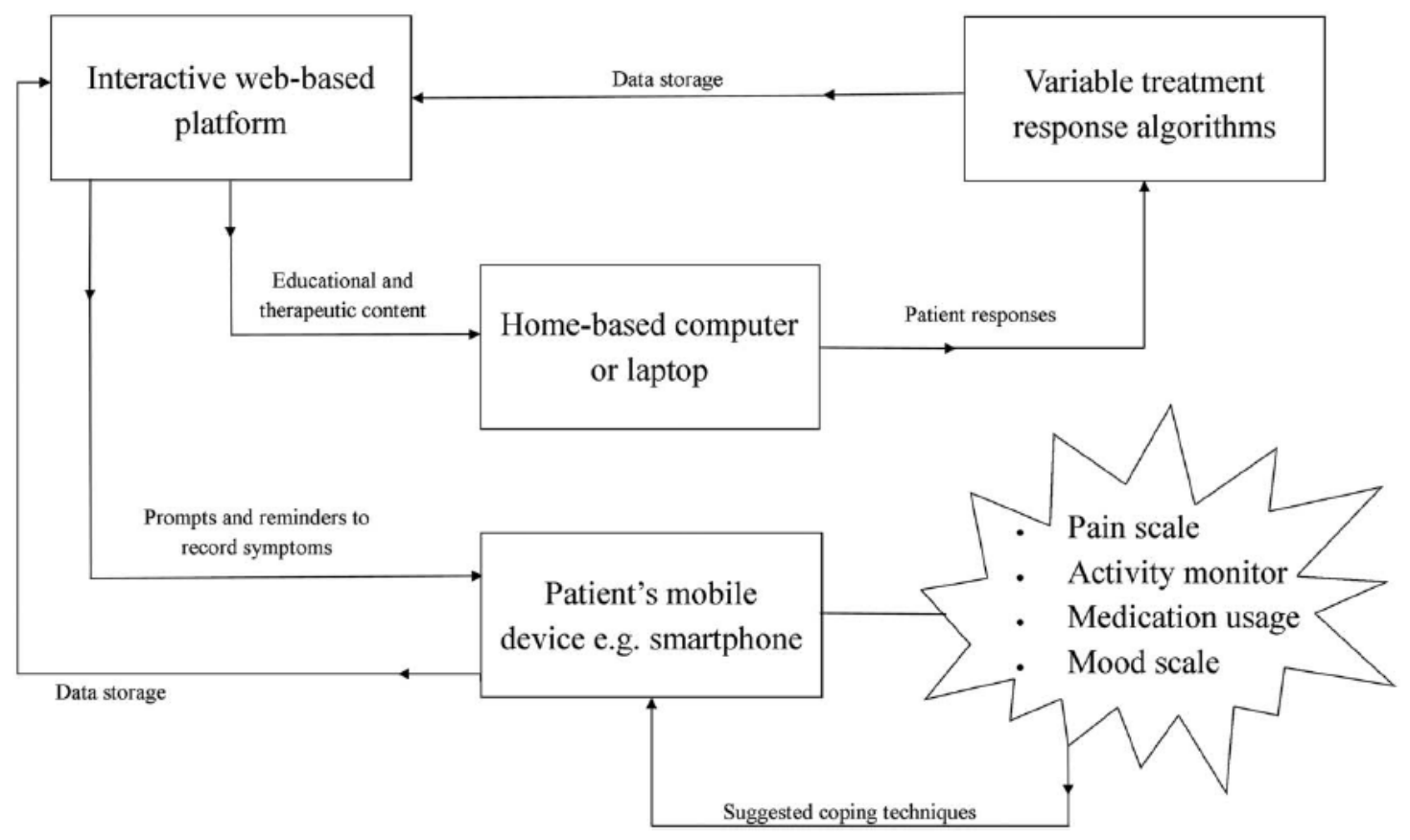

Figure 1. Sample e-pain intervention model with web-based platform and mobile-based symptom monitor. 


\section{References}

[1] Barr C, Marois M, Sim I, Schmid CH, Wilsey B, Ward D, Duan N, Hays RD, Selsky J, Servadio J, Schwartz M, Dsouza C, Dhammi N,Holt Z, Baquero V, MacDonald S, Jerant A, Sprinkle R, Servadio J. The PREEMPT study evaluating smartphone-assisted n-of- 1 trials in patients with chronic pain: study protocol for a randomized controlled trial. Trials 2015;16:67.

[2] Barton AJ. The regulation of mobile health applications. BMC Med 2012; 10:1-4.

[3] Beating the Blues. United Kingdom: Kings College London. Available at: http://www.beatingtheblues.co.uk/. Accessed April 25, 2016.

[4] British Psychological Society. Ethics guidelines internet-mediated research. Available at: www.bps.org.uk/publications/policy-and-guidelines/researchguidelines- policydocuments/research-guidelines-poli. Accessed January 8, 2016.

[5] BuhrmanM, Fredriksson A, Edstro"mG, Shafiei D, Ta“ rnqvist C, Ljo' tsson B, Hursti T, Gordh T, Andersson G. Guided Internet-delivered cognitive behavioural therapy for chronic pain patientswho have residual symptoms after rehabilitation treatment: randomized controlled trial. Eur J Pain 2013; 17:753-65.

[6] Canadian Medical Association. Guiding principles for physicians recommending mobile applications to patients. Available at: https:// www.google.ca/\#q5Cma1guidance1on1recommending1mobile1apps. Accessed January 8, 2016.

[7] Canadian Psychological Association. Draft ethical guidelines psychologists providing psychological services via electronic media. Available at:

http://www.cpa.ca/aboutcpa/committees/ethics/psychserviceselectronically. Accessed January 8, 2016.

[8] Daniel H, Snyder Sulmasy L; for the Health and Public Policy Committee of the American College of Physicians. Policy recommendations to guide the use of telemedicine in primary care settings: an American College of Physicians position paper. Ann Intern Med 2015;163:787-89.

[9] Davis MC, Zautra AJ. An online mindfulness intervention targeting socioemotional regulation in fibromyalgia: results of a randomized controlled trial. Ann Behav Med 2013;46:273-84.

[10] Dear BF, Gandy M, Karina E, Staplesa LG, Johnston L, Fogliati VJ, Wootton BM, Terides MD, Kayrouz R, Nicholson Perry K, Sharpe L, Nicholas MK, Titov N. The pain course: a randomised controlled trial examining an internet-delivered pain management program when provided with different levels of clinician support. PAIN 2015;156:1920-35.

[11] Dowd H, Hogan M, McGuire BE, Sarma K, Fish R, Davis M, Zautra A. Comparison of an online mindfulness-based cognitive therapy intervention with online pain management psychoeducation: a randomized controlled pilot study. Clin J Pain 2015;31:517-27.

[12] Eccleston C, Fisher E, Craig L, Duggan GB, Rosser BA, Keogh E. Psychological therapies (Internetdelivered) for the management of chronic pain in adults. Cochrane Database Syst Rev 2014:CD010152.

[13] eClinicCentre. Australia: Macquarie University. Available at: https://www.ecentreclinic.org/. Accessed April 25, 2016. 
[14] Federal Drug Administration. Mobile med applications. Available at: http://www.fda.gov/MedicalDevices/DigitalHealth/MobileMedicalApplications/default.htm. Accessed January 9, 2016.

[15] Fisher E, Law E, Palermo TM, Eccleston C. Psychological therapies (remotely delivered) for the management of chronic and recurrent pain in children and adolescents. Cochrane Database Syst Rev 2015:CD011118.

[16] Gilbody S, Littlewood E, Hewitt C, Brierley G, Tharmanathan P, Araya R, Barkham M, Bower P, Cooper C, Gask L, Kessler D, Lester H, Lovell K, Parry G, Richards DA, Andersen P, Brabyn S, Knowles $S$, Shepherd C, Tallon D, White D; REEACT Team. Computerised cognitive behaviour therapy (CCBT) as treatment for depression in primary care (REEACT trial): large scale pragmatic randomised controlled trial. BMJ 2015;351:h5627.

[17] Hayes S, Hogan M, O'Higgins S, Doherty E, Nic Gabhainn S, MacNeela P, Murphy AW, Kropmans T, Dowd H, O'Neill C, McGuire BE. Comparing the clinical- and cost-effectiveness of an internetdelivered Acceptance and Commitment Therapy (ACT) intervention with a waiting list control group among adults with chronic pain: study protocol for a randomized controlled trial. BMJ Open 2014;4. doi:10.1136/bmjopen-2014-005092.

[18] Henderson EM, Law EF, Palermo TM, Eccleston C. Case study: ethical guidance for pediatric ehealth research using examples from pain research with adolescents. J Ped Psychol 2012;37:111626.

[19] Hundert AS, Huguet A, McGrath PJ, Stinson JN, Wheaton M. Commercially available mobile phone headache diary apps: a systematic review. JMIR Mhealth Uhealth 2014;2:e36.

[20] IMS Institute for Healthcare Informatics. Patient Apps for Improved Healthcare: From Novelty to Mainstream. 2013. Available at: http://www.imshealth.com/en/thought-leadership/imsinstitute/reports/patient-appsfor-improved-healthcare. Accessed September 30, 2016.

[21] Irvine AB, Russell H, Manocchia M, Mino DE, Glassen TC, Morgan R,Gau JM, Birnie AJ, Ary DV. Mobile-Web app to self-manage low back pain: randomized controlled trial. J Med Internet Res 2015;17:e1.

[22] Kelders SM, Kok RN, Ossebaard HC, Van Gemert-Pijnen JE. Persuasive system design does matter: a systematic review of adherence to web based interventions. J Med Internet Res 2012;14:e152.

[23] King D, Greaves F, Exeter C, Darzi A. "Gamification": influencing health behaviours with games. J R Soc Med 2013;106:76-8.

[24] Lalloo C, Jibb LA, Rivera J, Agarwal A, Stinson JN. "There's a pain app for that": review of patienttargeted smartphone applications for pain management. Clin J Pain 2015;31:557-63.

[25] Law EF, Beals-Erickson SE, Noel M, Claar R, Palermo TM. Pilot randomized controlled trial of internet-delivered cognitive-behavioral treatment for pediatric headache. Headache 2015;55:141025.

[26] Lingley-Pottie P, McGrath PJ. A paediatric therapeutic alliance occurs with distance intervention. J Telemed Telecare 2008;14:236-40.

[27] MindSpot. Australia: Macquarie University. Available at: https://mindspot.org.au/. Accessed April 25, 2016. 
[28] MoodGym. Australia: Australian National University. Available at: http://moodgym.anu.edu.au. Accessed April 25, 2016.

[29] Nicholas MK. Expanding patients' access to help in managing their chronic pain. Pain: Clin Update 2015;xxii:1-8.

[30] Online Therapy USER. Canada: University of Regina. Available at: https://www.onlinetherapyuser.ca/. Accessed April 25, 2016.

[31] Palermo TM, Law EF, Fales J, Bromberg MH, Jessen-Fiddick T, Tai G. Internet-delivered cognitivebehavioral treatment for adolescents with chronic pain and their parents: a randomized controlled multicenter trial. PAIN 2016;157:174-85.

[32] Rosser BA, Eccleston C. Smartphone applications for pain management. J Telemed Telecare 2011;17:308-12.

[33] Schneider LH, Hadjistavropoulos HD. When in doubt, ask the audience: potential users' perceptions of Internet-delivered cognitive behavioural therapy for chronic pain. Pain Res Manag 2014;19:173-8.

[34] Sharpe L. Psychosocial management of chronic pain in patients with rheumatoid arthritis: challenges and solutions. J Pain Res 2016;9: 137-46.

[35] Shigaki CL, Smarr KL, Siva C, Ge B, Musser D, Johnson R. RAHelp: an online intervention for individuals with rheumatoid arthritis. Arthrit Care Res 2013;65:1573-81.

[36] Silvercloud. Ireland: Trinity College Dublin. Available at: http://www.silvercloudhealth.com/. Accessed April 25, 2016.

[37] Trompetter HR, Bohlmeijer ET, Fox JP, Schreurs KM. Psychological flexibility and catastrophizing as associated change mechanisms during online Acceptance \& Commitment Therapy for chronic pain. Behav Res Ther 2015;74:50-9.

[38] Vardeh D, Edwards RR, Jamison RN, Eccleston C. There's an app for that: mobile technology is a new advantage in managing chronic pain. Pain: Clin Update 2013;xxi:1-7.

[39] Wallace LS, Dhingra LK. A systematic review of smartphone applications for chronic pain available for download in the United States. J Opioid Man 2014;10:63-8.

[40] Web-MAP 2. US: University of Washington. Available at: http://www.webmap2.com/. Accessed April 25, 2016.

[41] Wozney L, McGrath PJ, Newton A, Huguet A, Franklin M, Perri K, Leuschen K, Toombs E, LingleyPottie $P$. Usability, learnability and performance evaluation of Intelligent Research and Intervention Software: A delivery platform for eHealth interventions. Health Informatics J 2016; 22:730-43. 